\title{
COMMUNITY OF PRACTICE (CoP) PADA PT. PUTRA KARANGETANG DI DESA POPONTOLEN KECAMATAN TUMPAAN KABUPATEN MINAHASA SELATAN
}

\author{
Indry M. Masinambow \\ Leonardus R. Rengkung \\ Agnes E. Loho
}

\begin{abstract}
The objective of research is to analyze Community of Practice based on the elements of Domain/share repertoire, Community/Mutual Engagement, and Practice/share repertoire as factors of PT. Putra Karangetang. This research was conducted from November 2015 until January 2016, started from preparation until report compilation. The data used in the form of primary data. This research was carried out with Stratified random sampling technique. In which 40 members of a population. Data analysis was done descriptively using a likert scale. The result showed that those elements of Domain/share repertoire, Community/Mutual Engagement, and Practice/share repertoire are strong elements as forming factor in the Community of Practice of official employee PT. Putra Karangetang, the result showed 93,37\% . Domain is the identity that has been set with particular interest that membership implies commitment, domain shaping up to be a collection of friends or network connections to achieve the goals of sustainable. Community as a means to gather people who share a common interest and engaged in discussions, they share knowledge and learn together. Practice as a process to improve skills, employees not only work in general but also share methods, techniques and experience to form a pattern of behavior and improve the skills of employees.
\end{abstract}

Key Words: Community of Practice, Domain, Community, Practice.

\begin{abstract}
ABSTRAK
Penelitian ini bertujuan untuk menganalisis Community of Practice berdasarkan elemenelemen domain/join enterprise, komunitas/mutual engagement, praktek/shared repertoire sebagai factor pembentuk Community Of Practice pada PT. Putra Karangetang. Penelitian ini dilaksakan pada bulan November 2015 hingga Februari 2016, mulai dari persiapan sampai penyusunan laporan. Data yang digunakan adalah data Primer. Penelitian ini dilakukan dengan teknik Stratified Random Sampling, dengan alokasi proporsional dan jumlah sample yang diambil adalah sebanyak 40 orang. Analisis data dilkukan secara deskriptif dengan menggunakan skala Likert. Hasil penelitian ini menunjukan bahwa elemen-elemen Domain/share repertoire, Komunitas/Mutual Engagement, Praktek/Share Repertoire adalah elemen-elemen yang kuat sebagai factor pembentuk Community of Practice, yaitu 93,37\% Domain yaitu identitas yang telah ditetapkan dengan minat tertentu yang keanggotaannya menyiratkan komitmen, domain membentuk menjadi kumpulan teman - teman atau jaringan koneksi untuk mencapai tujuan secara berkelanjutan. Komunitas menjadi sarana berkumpulnya orang-orang yang memiliki kepentingan bersama dan terlibat dalam aktivitas diskusi saling berbagi pengetahuan dan belajar bersama. Praktek sebagai suatu proses guna meningkatkan keterampilan dimana karyawan bukan hanya bekerja secara umum tetapi juga berbagi metode dan teknik serta pengalaman untuk membentuk pola prilaku dan meningkatkan keahlian karyawan.
\end{abstract}

Kata Kunci : Community of Practice, Domain, Komunitas, Praktek. 


\section{PENDAHULUAN}

\section{Latar Belakang}

Organisasi sebagai suatu sistem terbuka terus-menerus mengalami perubahan, karena selalu menghadapi tantangan baru dari lingkungan yang selalu berubah sehingga diperlukan interaksi atau hubungan antara orangorang yang terlibat didalamnya. Perubahan kodisi sosial ini tergantung kepada bakat dan inisiatif manusia yang dinamis agar selalu dapat menyesuaikan diri dengan kendala-kendala serta perubahan yang terjadi. Organisasi pembelajar akan mampu bertahan karena mempunyai pengetahuan dan inovasi-inovasi untuk menghadapi masalah-masalah internal dan eksternal dalam organisasi.

Organisasi dapat menyesuaikan diri dengan mengadakan berbagai perubahan dalam dirinya dengan meningkatkan proses pembelajaran sehingga dapat menjadi organisasi pembelajar. Organisasi pembelajar membutuhkan masyarakat yang berpengetahuan untuk mengembangkan pengetahuan umum. Salah satu indikasi organisasi pembelajar adalah adanya kegiatan berbagi pengetahuan dan berbagi pengalaman guna merangsang interaksi di antara para anggotanya. Terdapat beberapa pendekatan terkait dengan organisasi yang berhadapan dengan lingkungan yang tidak pasti yaitu Resources Based View, Knowing Organization, Dynamic Capabilities dan salah satunya adalah Community of Practice (Wenger. 2002).

Wenger (2002) menyebutkan bahwa Community of practice adalah bentuk suatu kelompok diskusi dimana sekumpulan orang yang memiliki keinginan untuk berbagi menyelesaikan suatu permasalahan, memiiki suatu keahlian atau ketertarikan terhadap suatu topik tertentu, merupakan suatu cara inovatif untuk membentuk dan berbagi pengetahuan organisasi, dan menurut Lave dan Wenger dalam Atmoko (2009), Community of practice merupakan sebuah sistem aktifitas dimana para anggotanya berbagi pemahaman mengenai apa yang sedang dikerjakan bagaimana menginterpretsikan kejadian, dan apa makna dalam konteks yang lebih luas dari kehidupan dan komunitas mereka.

Tiga karakteristik yang mencirikan Community of Practice yaitu domain/join enterprise, komunitas/mutual engagement, dan praktek/shared repertoire (Nikols 2003; Zulaiha
2008) Community of Practice mungkin memiliki iklim inovasi yang bisa menunjukan potensi anggota dalam berkontribusi terhadap inovasi organisasi hingga tercapainya keberhasilan suatu organisasi perusahaan.

Tepung kelapa telah menjadi produk ekspor unggulan di Sulawesi Utara. Pasarannya telah memenuhi permintaan di lima Negara masing-masing Belgia, Austria, Brasil, Belanda, dan Jerman.

Salah satu perusahaan tepung kelapa di Sulawesi utara adalah PT. Putra Karangetang yang berlokasi di Desa Popontolen kecamatan Tumpaan Kabupaten Minahasa Selatan, perusahaan ini beroperasi sejak tahun 2001, Perusahaan ini telah mengekspor tepung kelapa keberbagai Negara dan memperoleh keuntungan yang cukup besar. Berbagai macam dinamika lingkungan organisasi telah dihadapi oleh PT. Putra Karangetang. Keberhasilan yang terjadi di PT. Putra Karangetang diperkirakan karena adanya praktek Community of Practice.

Penting untuk melihat apakah suatu perusahaan mempunyai Community of Practice, Proses ini dapat menjadi sulit ketika CoP menjadi kelompok yang spontan dimana organisasi tidak menyadari keaadaannya (Ikro 2009). Suatu hal yang memungkinkan untuk meggambarkan $\mathrm{CoP}$ didalam sebuah organisasi perusahaan adalah menganalisa keberadaan kelompok tersebut, dengan pemimpin yang jelas dan anggota dengan kesamaan minat atau kepentingan didalam perusahaan.

\section{Rumusan Masalah}

Bagaimana kemampuan dari elemenelemen dari CoP yaitu domain/join enterprise, komunitas/mutual engagement, praktek/shared repertoire sebagai karakteristik yang mencirikan adanya CoP dalam organisasi perusahaan PT. Putra Karangetang?

\section{Tujuan dan Manfaat Penelitian}

Penelitian ini bertujuan untuk menganalisis kemampuan dari elemen-elemen dari Community of Practice yaitu domain/join enterprise, komunitas/mutual engagement, praktek/shared repertoire sebagai karakteristik yang mencirikan adanya $\mathrm{CoP}$ dalam organisasi perusahaan PT. Putra Karangetang 
Penelitian ini diharapkan dapat memberikan kontribusi bagi para anggota organisasi perusahaan, terlebih khusus kepada kelompok anggota organisasi perusahaan PT. Putra Karangetang untuk menyadari perlunya membentuk Community of Practice, dan memanfaatkan terbentuknya Community of Practice dengan sebaik mungkin.

\section{METODELOGI PENELITIAN}

\section{Waktu dan Lokasi Penelitian}

Penelitian ini dilakukan di PT. Putra Karangetang, desa Popontolen kecamatan Tumpaan Kabupaten Minahasa Selatan selama tiga bulan, yaitu pada bulan November 2015 sampai bulan Januari 2016, mulai dari persiapan, pengambilan data, sampai pada penyusunan laporan penelitian.

\section{Metode Pengumpulan Data}

Data yang digunakan dalam penelitian ini adalah data primer dengan pemgambilan data menggunakan metode survey serta menggunakan kuesioner.

\section{Konsep Pengukuran Variabel}

Variabel-variabel yang digunakan dalam penelitian ini adalah, Domain (Joint Enterprise) diukur dari identitas, komitmen, tujuan, misi, tekad untuk mencapai sesuatu secara berklanjutan., Melakukan pekerjaan untuk kemajuan perusahaan. Komunitas (Mutual Engagement) diukur dari Kelompok yang saling berinteraksi, aktivitas diskusi diluar jam pekerjaan saling menolong, saling berbagi informasi serta proses belajar bersama. Praktek (Shared Repertoire) diukur dari, penerapan metode, saling berbagi cerita tentang pekerjaan, saling berbagi teknik mengatasi masalah, saling berbagi pengalaman tentang pekerjaan, terbentuknya pola prilaku, serta peningkatan keahlian.

\section{Teknik Analisis Data}

Analisis data yang digunakan dalam penelitian ini adalah secara deskriptif. dengan menggunakan skala likert. untuk mengukur Community of Practice akan disusun 18 pertanyaan dengan total responden 40 orang. Setiap jawaban dihubungkan dengan bentuk pernyataan atau dukungan diungkapkan dengan kata-kata yaitu jenjang 1 (tidak setuju), 2 (netral), 3 (setuju).

Dengan cara perhitungan skor masing-masing pertanyaan:

Jumlah Skor tiap Kritrium = Capaian Skor X Jumlah Responden

Jumlah skor ideal untuk setiap pernyataan (skor tertinggi) $=120$

Jumlah skor terendah $=40$

Cara perhitungan skor keseluruhan untuk mengetahui Community of Practice pada karyawan perusahaan PT. Putra Karangetang

Jumlah skor seluruh kriterium = capaian jumlah skor X Jumlah Responden X Instrumen Pertanyaan

Jumlah skor ideal untuk keseluruhan pernyataan = 2.160

Jumlah skor terendah $=720$

Tingkat praktek CoP

$$
=\frac{\text { Jumlah Skor Hasil Pengumpulan Data }}{\text { Jumlah skor ideal (tertinggi) }} \times 100 \%
$$

Keterangan Kriteria interpretasi skor Community of Practice:

Angka 0\%-33,3\% = Rendah

Angka 33,4\% - 66,6\% = Cukup

Angka 66,7\% - 100\% = Tinggi

\section{HASIL DAN PEMBAHASAN}

\section{Gambaran mum PT.Putra Karangetang}

PT. Putra Karangetang adalah perusahaan yang berbentuk perseroan terbatas (PT) dan merupakan perusahaan yang menghasilkan tepung kelapa. Terletak di Desa Popontolen, Kecamatan Tumpaan, Kabupaten Minahasa Selatan, Propinsi Sulawesi Utara, Indonesia. Perusahaan ini berdiri sejak tahun 2001 dan telah mengekspor tepung kelapa ke berbagai Negara di dunia. Dengan memiliki karyawan sebanyak 153 orang. Dan mempekerjakan tenaga kerja pria dan wanita.

\section{Community Of Practice}

Elemen-elemen domain/join enterprise, komunitas/mutual engagement, praktek/shared repertoire sebagai faktor pembentuk Community Of Practice, menjadi tidak dapat terpisahkan. Elemen-elemen tersebut merupakan variabel yang berbeda antara satu dengan yang lain namun 
ketiganya saling berhubungan dan berkaitan erat. Tingkat kekuatan dari elemen-elemen domain/join enterprise, komunitas/mutual engagement, praktek/shared repertoire sebagai faktor pembentuk Community of Practice diukur melalui variabel pendukung ketiga elemen tersebut. menggunakan skala ukur Likert dengan jenjang 1 (tidak setuju), 2 (netral), 3 (setuju).

Hasil tabulasi atas elemen-elemen pembentuk Community Of Practice dan variabel pendukungnya, dapat dilihat pada tabel. Penjelasan mengenai ketiga elemen pembentuk Community of Practice pada PT. Putra Karangetang serta variabel-variabel pendukung akan dipaparkan sebagai berikut:
Domain dapat diartikan sebagai identitas yang telah ditetapkan dengan minat tertentu yang keanggotaannya menyiratkan komitmen kepada domain. Sebegai elemen pembentuk Community of Practice. Domain membentuk menjadi kumpulan teman-teman atau jaringan koneksi untuk mencapai sesuatu secara berkelanjutan Proses Domain/join enterprise perusahaan didasarkan pada identitas, minat, komitmen, tujuan, tekad, serta misi kedepan untuk kemajuan perusahaan. Pengukuran Domain/join enterprisedilakukan melalui 8 variabel pendukung yang disajikan lewat penyataan kepada karyawan perusahaan.

\section{Domain/join enterprise}

Tabel 1. Pengukuran Variabel Domain/Joint Enterprise PT.Putra Karangetang

\begin{tabular}{|c|c|c|c|c|}
\hline No & PERNYATAAN & $\begin{array}{l}\text { TOTAL } \\
\text { SKOR }\end{array}$ & $\begin{array}{l}\text { INDEK } \\
\text { S CoP }\end{array}$ & $\begin{array}{l}\text { INTERPRETA } \\
\text { SI }\end{array}$ \\
\hline 1 & $\begin{array}{l}\text { Karyawan perusahaan memiliki identitas yang telah } \\
\text { ditetapkan dalam jenis pekerjaan tertentu }\end{array}$ & 120 & 100 & Tinggi \\
\hline 2 & $\begin{array}{l}\text { Karyawan perusahaan memiliki minat yang sama } \\
\text { dengan pekerjaan yang dimiliki }\end{array}$ & 101 & 84,16 & Tinggi \\
\hline 3 & $\begin{array}{l}\text { Karyawan perusahaan memiliki komitmen tersirat } \\
\text { kepada domain pekerjaan yang telah ditetapkan }\end{array}$ & 106 & 88,33 & Tinggi \\
\hline 4 & $\begin{array}{l}\text { Karyawan perusahaan melakukan pekerjaan guna } \\
\text { mencapai tujuan yang lebih besar untuk kemajuan } \\
\text { perusahaan }\end{array}$ & 120 & 100 & Tinggi \\
\hline 5 & $\begin{array}{l}\text { Karyawan perusahaan memiliki tekad yang kuat } \\
\text { untuk mencapai tujuan demi kemajuan yang } \\
\text { berkelanjutan }\end{array}$ & 120 & 100 & Tinggi \\
\hline 6 & $\begin{array}{l}\text { Karyawan perusahaan yang tergabung dalam jenis } \\
\text { pekerjaan yang sama memiliki komitmen pada jenis } \\
\text { pekerjaan yang dimiliki }\end{array}$ & 120 & 100 & Tinggi \\
\hline 7 & $\begin{array}{l}\text { Karyawan perusahaan memiliki "misi" atau dalam } \\
\text { istilah sederhana "mengacu pada sesuatu" dalam } \\
\text { melaksanakan pekerjaan }\end{array}$ & 111 & 92,5 & Tinggi \\
\hline 8 & $\begin{array}{l}\text { Karyawan perusahaan melakukan pekerjaan bukan } \\
\text { hanya untuk kepentingan pribadi tapi juga untuk } \\
\text { kemajuan perusahaan }\end{array}$ & 120 & 100 & Tinggi \\
\hline
\end{tabular}
Sumber: Diolah dari data primer 2016

Tabel 1 menunjukan bahwa terdapat 8 indikator pembentuk Community of Practice dalam elemen Domain/Join Enterprise dimana pernyataan 1 , pernyataan 4 , pernyataan 5 , pernyataan 6 , dan pernyataan 8 mendapat indeks tertinggi yaitu $100 \%$ dengan interpretasi tinggi. 
Sedangkan pernyataan 2 mendapat indeks CoP $84,16 \%$, pernyataan 3 mendapat indeks $\mathrm{CoP}$ $88,33 \%$, pernyataan 7 mendapat indeks CoP $92,5 \%$ dan semuanya mendapat interpretasi tinggi karena diatas $66,6 \%$.

\section{Komunitas/Mutual Engagement} Komunitas merupakan sarana berkumpulnya orang-orang yang memiliki kepentingan bersama, keninginan untuk berbagi dan berkomunikasi diantara anggota sesuai dengan kepentingan bersama (Delobelle, 2008). Sebagai elemen pembentuk Community of Practice komunitas memiliki anggota yang terlibat dalam aktivitas diskusi dan berbagi informasi untuk memenuhi minat dalam domain mereka.Para anggota CoP berinteraksi satu sama lain. Pengukuran Komunitas/Mutual Engagement dilakukan melalui 4 variabel pendukung yang disajikan lewat pernyataan kepada karyawan perusahaan.

Tabel 2 menunjukan bahwah terdapat 4 indikator pembentuk Community of Practice pekerjaan dan membentuk pola prilaku karyawan. Pengukuran Praktek/Share Repertoire dilakukan melalui 6 variabel pendukung yang disajikan lewat pernyataan kepada karyawan perusahaan. dalam elemen Komunitas/Mutual Engagement dimana pernyataan 9, dan pernyataan 12 mendapat indeks tertinggi yaitu $100 \%$ dengan interpretasi tinggi. Sedangkan pernyataan 10 mendapat indeks CoP 85,83\%, pernyataan 11 mendapat indeks CoP 99,16\% dan semuanya mendapat interpretasi tinggi karena diatas 66,6\%.

\section{Praktek/Share Repertoire}

Praktek diartikan sebagai suatu proses guna meningkatkan keterampilan. Praktek/share repertoire dalam Community of Practice dimana para karyawan tidak hanya bekerja secara umum tapi juga dalam metode, alat dan teknik bahkan pengalaman.

Proses Praktek/Share Repertoire perusahaan didasarkan pada praktek berbagi metode, alat dan teknik serta pengalaman dari para karyawan. Aktivitas praktek ini diharapkan akan mampu meningkatkan keahlian dalam

Tabel 2. Pengukuran Variabel Komunitas/Mutual Engagement PT.Putra Karangetang

\begin{tabular}{ccccc}
\hline No & PERNYATAAN & TOTAL & INDEKS & INTERPR \\
& SKOR & CoP & ETASI
\end{tabular}

\begin{tabular}{clllc}
\hline 9 & $\begin{array}{l}\text { Karyawan perusahaan memiliki hubungan kelompok } \\
\text { yang sering bertemu dan saling berinteraksi }\end{array}$ & 120 & 100 & Tinggi \\
\hline 10 & $\begin{array}{l}\text { Karyawan perusahaan terlibat dalam aktivitas diskusi } \\
\text { tentang proses pekerjaan diluar jam pekerjaan }\end{array}$ & 103 & 85,83 & Tinggi \\
\hline 11 & $\begin{array}{l}\text { Karyawan perusahaan saling membantu / menolong } \\
\text { satu sama lain dalam mejalankan tugas dan pekerjaan }\end{array}$ & 119 & 99,16 & Tinggi \\
\hline
\end{tabular}

12 Karyawan PT. Putra Karangetang yang memiliki jenis

$120 \quad 100 \quad$ Tinggi pekerjaan yang sama saling berinteraksi dan belajar bersama

Sumber: Diolah dari data primer 2016 
Tabel 3 menunjukkan bahwa terdapat 6 indikator pembentuk Community of Practice dalam elemen Praktek/Share Repertoire dimana pernyataan 13 , pernyataan 14 , dan pernyataan 16, mendapat indeks tertinggi yaitu $100 \%$ dengan interpretasi tinggi. Pernyataan 15 mendapat indeks CoP 92,5\%, pernyataan 18 mendapat indeks CoP 87,5\%, dengan interpretasi tinggi. Sedangkan pernyataan 17 mendapat indeks CoP 50,83\% dengan interpretasi cukup karena kurang dari $66,6 \%$ dan lebih dari 33,4\%.

\section{Tabel 3. Pengukuran Variabel Praktek/Share Repertoire PT.Putra Karangetang}

\begin{tabular}{clccc}
\hline No & \multicolumn{1}{c}{ PERNYATAAN } & $\begin{array}{c}\text { TOTAL } \\
\text { SKOR }\end{array}$ & INDEKSCoP & $\begin{array}{c}\text { INTERPRE } \\
\text { TASI }\end{array}$ \\
\hline 13 & $\begin{array}{l}\text { Karyawan PT. Putra Karangetang mampu menerapkan metode } \\
\text { dan teknik dalam penggunaan alat untuk kelancaran pekerjaan }\end{array}$ & 120 & 100 & Tinggi \\
\hline 14 & $\begin{array}{l}\text { Karyawan PT. Putra Karangetang saling berbagi metode yang } \\
\text { dimiliki dalam penyelesaian pekerjaan }\end{array}$ & 120 & 100 & Tinggi \\
\hline 15 & $\begin{array}{l}\text { Karyawan PT. Putra Karangetang saling berbagi teknik } \\
\text { mengatasi masalah dalam pekerjaan }\end{array}$ & 111 & 92,5 & Tinggi \\
\hline 16 & $\begin{array}{l}\text { Karyawan PT. Putra Karangetang saling berbagi pengalaman } \\
\text { tentang pekerjaan. }\end{array}$ & 120 & 100 & Tinggi \\
\hline 17 & $\begin{array}{l}\text { Pola prilaku Karyawan PT. Putra Karangetang terbentuk dari } \\
\text { kelompok komunitas diskusi }\end{array}$ & 61 & 50,83 & Cukup \\
\hline 18 & $\begin{array}{l}\text { Keahlian Karyawan PT. Putra Karangetang dalam pekerjaan } \\
\text { terbentuk dari praktek yang saling berbagi }\end{array}$ & 105 & 87,5 & Tinggi \\
\hline Sul & &
\end{tabular}

Sumber: Diolah dari data primer 2016 
Penelitian ini menunjukan bahwah dari 18 indikator, indikator 1 sampai dengan indikator 16 serta indikator 18 mendapatkan skor pada indeks yang tergolong tinggi $(66,7-$ $100 \%$ ). Walaupun pada indikator 17 yakni elemen praktek/share repertoire hanya mendapatkan skor 61 pada indeks yang tergolong cukup 50,83\% (33,4\%-66,6\%). Hal ini menunjukan bahwah Community of Practicepada PT. Putra Karangetang tergolong tinggi namun tergolong cukup pada penyataan 17 bahwah Pola prilaku karyawan perusahaan terbentuk dari kelompok komunitas diskusi, karyawan beranggapan bahwah pola prilaku mereka tidak sepenuhnya terbentuk dari aktifitas diskusi yang mereka lakukan antar sesasa karyawan tetapi juga pola prilaku karyawan terbentuk dari aktivitas mereka masing-masing diluar pekerjaan, baik dalam keluarga, masyarakat, dansebagainya. Berdasarkan data yang dihimpun dari

sebanyak 18 instrumen pernyataan yang diajukan kepada 40 orang responden, maka diperoleh total skor 2.017. secara persentase, angka indeks Community of Practice pada PT. Putra Karangetang terletak pada $\mathrm{CoP}=$

Jumlah skor hasil pengumpulan data Jumlah skor ideal (tertinggi)

$$
=\frac{2017}{2160} \times 100 \%=93,37 \%
$$

Berdasarkan hasil analisis menggunakan skala likert, maka dapat diketahui bahwah angka indeks Community of Practice pada PT. Putra Karangetang berada pada titik 93,37\% dan tergolong tinggi, artinya tanpa disadari Community of Practice telah ada pada PT. Putra Karangetang.

\section{KESIMPULAN}

Penelitian ini menunjukan bahwah terdapat Community of Practice pada PT. Putra Karangetang. Artinya Community of Practice pada PT. Putra Karangetang adalah tinggi yaitu 93,37\% elemen pembentuk Community of Practice yaitu domain/join enterprise, komunitas/mutual engagement, dan praktek/share repertoire saling berkaitan erat dalam membentuk Community of Practice. Dapat disimpulkan bahwa community of Practice ini menjadi tepat bertukar pikiran berbagi informasi, berbagi pengetahuan (transfer learning) bagi para karyawan perusahaan PT. Putra Karangetang untuk meningkatkan keterampilan tenaga kerja perusahaan Interpretasi hasil pada pernyataan pola prilaku karyawan terbentuk dari aktivitas saling berbagi dengan angka indeks terendah yaitu 50,83\%. Community of Practice dianggap masih tergolong cukup untuk membentuk pola prilaku karyawan. Karyawan menganggap bahwah pola prilaku mereka tidak hanya terbentuk dari kelompok diskusi praktek saling berbagi dalam CoP tapi juga terbentuk dari aktifitas mereka masing-masing diluar pekerjaan baik dalam keluarga maupun dalam masyarakat.

\section{SARAN}

Berdasarkan perolehan hasil data yang menunjukan PT. Putra Karangetang memiliki Community of Practice yang tinggi, maka disarankan agar karyawan perusahaan tetap terus mempertahankan bahkan meningkatkan terbentuknya $\mathrm{CoP}$ dengan meningkatkan elemen-elemen domain/join enterprise, komunitas/mutual engagement, dan praktek/shared repertoire sebagai faktor pembentuk.

Peningkatan elemen domain/join enterprise dilakukan dengan mempertahankan bahkan meningkatkan komitmen tersirat kepada pekerjaan, mencintai pekerjaan yang dimiliki serta memiliki tujuan kedepan dalam melaksanakan pekerjaan. Untuk memperkuat komunitas/mutual engagement diharapkan juga karyawan lebih melibatkan diri dalam aktifitas diskusi tentang pekerjaan diluar jam pekejaan, serta saling menolong satu sama lain. Diharapkan aktifitas diskusi ini terjadi bukan hanya sesama karyawan tapi juga lower manajemen dan top manajemen. Adapun praktek/share repertoire yang wajib kembangkan dengan saling berbagi metode dan teknik dalam pekerjaan juga berbagi teknik mengatasi masalah. Diharapkan juga praktek saling berbagi ini akan mampu meningkatkan 
keahlian dalam pekerjaan serta membentuk pola prilaku karyawan menjadi lebih baik.

Bagi pimpinan perusahaan atau top manjemen di sarankan agar menyadari terbentuknya Community of Practice, dan memperhatikan peningkatan setiap elemen pembentuk $\mathrm{CoP}$ untuk mengevaluasi kekuatan organisasi perusahaan dalam hal ini adalah tenaga kerja untuk menghadapi lingkungan bisnis yang dinamis. Perusahaan diharapkan untuk dapat memfasilitasi keberadaan Community of Practice dengan menyediakan waktu khusus untuk para karyawan saling berinteraksi bertukar pikiran sebagai bagian dari community of Practice. Misalkan mengadakan afternoon café, serta menyediakan tempat karena para karyawan lebih sering berinteraksi satu sama lain saat selesai bekerja di sore hari.

\section{DAFTAR PUSTAKA}

Atmoko. Andreo W., 2009.Dinamika Knowing Organization di Perusahaan

Konsultan Manajemen SDM: Studi Kasus Daya Dimensi Indonesia.

Disertasi. Universitas Indonesia. Jakarta.

Delobelle, Vanina., 2008. Corporate Community Management. Sandy. Inc

Ikro. Mohamad, 2009. "Membangun Community of Practice (CoP) untuk Menumbuhkan budaya knowledge sharing. (Diakses Mei 2015).

Nickols. Fred, 2003.Communities of Practice : A Start - Up kit.Distance Consulting

Wagner. Tina M. Chindgren, 2009. Examining the Relationship between Communities of Practice and Climate of Innovation in the U.S. Federal

Government Environtmen

$\begin{array}{ccc}\text { Wenger. E, Richard McDermott,\& } & \text { William } \\ \text { Snyder, 2002. } & \text { Cultivating } \\ \text { Communities of Practice } & : \text { A Guide } \\ \text { to Managing } & \text { Knowledge }\end{array}$

(Buston,MA:Harvard Business School press)

Zulaiha. Siti, 2008. "Community of Practice sebagai Sarana Efektif Berbagi

Pengetahuan dalam suatu Organisasi” e-Indonesia Initiative (ell2008), Jakarta.(Diakses Mei 2015) 